\title{
"El ángel de los perdedores": una mirada antropológica sobre trayectorias delictivas, moralidades y experiencias espirituales con San La Muerte en una villa de Córdoba, Argentina
}

\author{
"The angel of losers": an anthropological look about criminal \\ Marina Liberatori ${ }^{*}$ \\ Instituto de Antropología de Córdoba (Idacor) \\ Consejo Nacional de Investigaciones Científicas y Técnicas (Conicet), Argentina
}

trajectories, moralities and spiritual experiences with San La Muerte in a slum of Córdoba, Argentina

D0I: $10.22380 / 2539472 X .1373$

\begin{abstract}
$\overline{\text { RESUMEN }}$
En este artículo analizaré el caso de dos residentes del barrio Villa La Tela, cuyas experiencias espirituales con San La Muerte regulan los sentidos con los que construyen valores morales y complejizan las relaciones con familiares y vecinos. Veremos cómo esto se vincula con el hecho de vivir en una zona periférica y empobrecida de la ciudad, socialmente estigmatizada. Mostraré de qué modo las trayectorias morales que ellos construyen $-y$ que se asocian con el mal y el delito - se articulan con la de San La Muerte, con quien establecen relaciones recíprocas de confianza, respeto, amor y favores. Esto permite reflexionar sobre las fronteras fluctuantes y porosas entre el bien y el mal como categorías morales con las cuales las personas significan y dan sentido al mundo.
\end{abstract}

Palabras clave: delito, asentamientos urbanos, moralidades ambiguas, cultos paganos.

\section{ABSTRACT}

In this article I will analyze the case of two residents of the Villa La Tela neighborhood, whose spiritual experiences with San La Muerte regulate the ways in which they build moral values and establish complex relationships with relatives and neighbors. We will see how this is linked to living in a peripheral and impoverished area of the city, socially stigmatized. I will show how their moral trajectories - that are associated with evil and crime - are articulated with that of San La Muerte, with whom they establish reciprocal relationships of trust, respect, love and favors. This allows us to reflect on the fluctuating and porous boundaries between good and evil as moral categories with which people give meaning to the world.

Keywords: crime, urban slums, ambiguous moralities, pagan cults. 


\section{Introducción}

En este artículo analizaré cómo las experiencias espirituales de dos vecinos de Villa La Tela (Córdoba, Argentina) con San La Muerte regulan los sentidos a partir de los cuales construyen valores morales y las relaciones sociales con sus familiares y vecinos. San La Muerte es un santo de moralidad ambigua porque tiene la posibilidad de movilizar tanto el bien como el mal (Míguez 2012); es un santo pagano porque no está aceptado por la Iglesia católica, aunque tiene carácter católico por su estructura devocional (Calzato 2008). El culto tiene origen en las provincias de Corrientes y Entre Ríos y se fue diseminando en toda Argentina. Según este autor, San La Muerte se caracteriza por el hecho de que sus seguidores provienen de zonas marginales. Mis entrevistados tenían diversas opiniones - a veces contrarias entre sí- sobre su procedencia y culto. Iván, por ejemplo, decía que era un curandero proveniente de la provincia de Entre Ríos que se dedicaba a proteger a los pobres y a robarles a los ricos. Diversos autores (Carozzi 2005; Chumbita 2013; Míguez 2008, 2012), retomando a Hobsbawm, analizan cómo el prototipo social del ladrón noble se relaciona con la construcción mítica de ladrones rurales y villanos urbanos desde las clases subordinadas. Así, para estos autores, la figura de San La Muerte aparece en las leyendas como una especie de Robin Hood que se dedicaba a ayudar a los pobres por sobre los intereses y abusos de los ricos.

El culto a San La Muerte se asemeja a otros de procedencia pagana característicos de Latinoamérica, como Sarita Colonia en Perú, el candomblé y umbanda en Brasil, la Santa Muerte en México o María Lionza en Venezuela, por citar algunos. Todos ellos poseen particularidades que los vuelven únicos y difíciles de comprender fuera de su contexto local. Entre sus diferencias encontramos, por ejemplo, la capacidad de ser incorporados ${ }^{1}$, como en el caso de los orixás, las entidades umbanda y María Lionza; a su vez, los seguidores de Sarita Colonia y San La Muerte están vinculados con el delito. Sin embargo, todos estos cultos coinciden en su origen sincrético de las culturas afro, indígena y europea; también en su moralidad ambigua, puesto que tienen tanto la capacidad de realizar el bien como la de castigar duramente a quienes incumplen sus promesas (Canals 2012).

Se trata de cultos que podrían caracterizarse como religiosidades populares. Ceriani (2013) señala las ventajas y desventajas de englobar a los estudios que ocupan “posiciones periféricas” en el campo religioso bajo una categoría tan

1 Incorporar significa que la divinidad ingresa en el cuerpo del devoto. Este último toma las características de la divinidad por el tiempo que dura la incorporación. Generalmente esto acontece durante celebraciones y rituales. 
Figura 1. Estatuas de San La Muerte en la gruta de Sissy

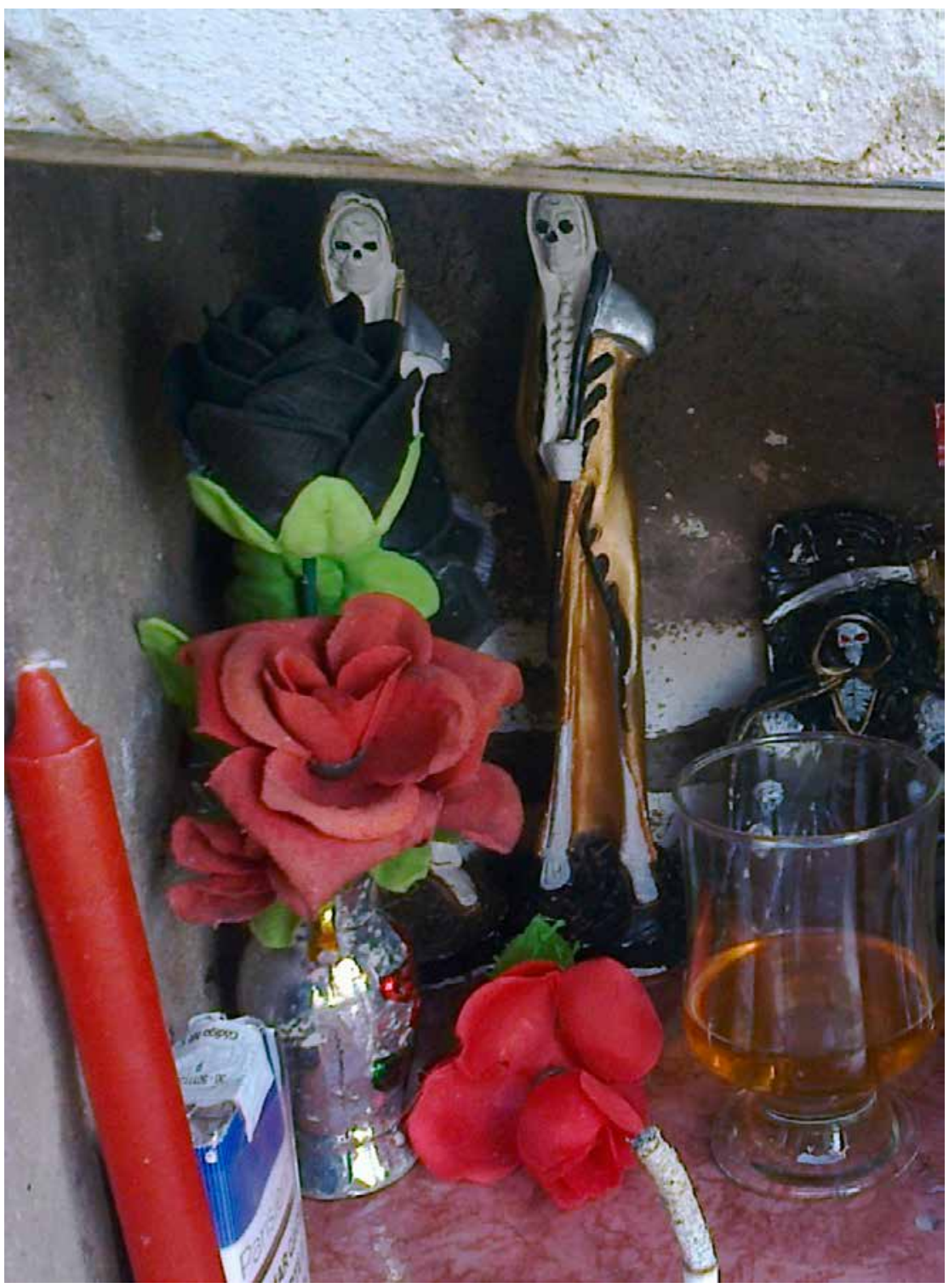

Fuente: fotografía de la autora, 2015.

polivalente, controvertida y compleja como la de religión. Así, los cultos a santos populares "jugarían en ligas menores" respecto de las "grandes ligas" en las cuales se ubica al Estado y a la Iglesia católica en la sociedad argentina (Ceriani 2013, 14). Por su parte, Martín (2007) advierte sobre las dificultades de englobar a estos cultos en una categoría como la de religiosidad popular y propone en 
cambio pensar en prácticas o experiencias espirituales. En esta misma vía, Goldman $(2003,2006)$ problematiza la categoría de creencia que, según él, se construye desde la racionalidad del investigador e implica que los otros con quienes trabaja tienen apenas creencias. Propone, en cambio, pensar en las experiencias desde las cuales un individuo se relaciona "con el cosmos, con la naturaleza, consigo mismo, con el grupo” (Goldman 2006, 167, traducción propia) y construye saberes legítimos sobre el mundo. En este sentido, dejarnos afectar por estas experiencias nos permite mirar las cosas desde un punto de vista más cercano al de las personas con las que trabajamos.

Favret-Saada (2005), en estrecha relación con la propuesta de Goldman, afirma que los antropólogos, en no pocas ocasiones, han hecho caso omiso a la experiencia humana en el campo, lo cual se vincula con la gran distancia entre los etnólogos y los nativos. La autora, quien trabaja sobre hechicería, sostiene que en la literatura sobre el tema ha habido siempre una marcada distinción entre las personas que creen en la brujería y los antropólogos (racionales) que no se dejan contaminar por su objeto. Por otra parte, analiza cómo la temática de la hechicería ha sido subestimada y asociada siempre con el atraso y la ignorancia. Por tanto, dejarse afectar no tiene que ver con la empatía relacionada con la distancia a través de la cual el antropólogo representa el mundo de los otros, sino que supone dejarse llevar por las percepciones y pensamientos de los nativos, asumiendo el riesgo de que se modifiquen los propios (Favret-Saada 2005). Teniendo en cuenta lo anterior, considero que abordar el vínculo entre los vecinos de Villa La Tela y San La Muerte desde la categoría de experiencia es una cuestión de respeto etnográfico hacia ellos, hacia sus certezas, procesos y prácticas de vida.

Sissy², una mujer de unos cuarenta años, vivía en La Tela desde hacía más de diez cuando la conocí en 2015. Empezó a relacionarse con San La Muerte a partir de un sueño que tuvo mientras estaba detenida en Bouwer ${ }^{3}$ por vender droga. El santito la ayudaba en sus actividades ilegales y ella le devolvía los favores cuidando de su gruta, ofrendándole objetos preciados para él. También la protegió y la empoderó para defenderse de los golpes que recibía por parte de su marido y de sus compañeras de encierro.

2 Todos los nombres que aparecen en este manuscrito son ficticios, para proteger la identidad e intimidad de las personas con las que trabajé.

3 El Complejo Carcelario n. 1 Reverendo Francisco Luchesse se encuentra ubicado en la localidad de Bouwer, a las afueras de la ciudad de Córdoba. Se construyó en el año 2003 durante la gobernación de José Manuel de la Sota. Está dividido en cuatro módulos donde se alojan hombres, el Establecimiento Penitenciario n. 3 (EP3) y el Complejo Esperanza para jóvenes "en conflicto con la ley penal". 
Iván, un joven de veintidós años, vivía en La Tela desde que era niño. Tuvo una infancia difícil, signada por la pobreza y la violencia doméstica. Dejó la escuela y comenzó a robar y a drogarse desde muy temprana edad. Conoció a San La Muerte en la cárcel, a través de una aparición que le ayudó a dar un giro en su vida. A cambio, Iván construyó una gruta en donde le ofrendaba objetos que intercambiaba por pedidos y favores. Sin embargo, esta le acarreó algunos problemas con sus vecinos.

A partir de mi trabajo etnográfico, mostraré cómo las trayectorias morales que estas personas construyen en la villa se van articulando con las del santo. Veremos que tanto Sissy e Iván - por causa de sus trayectorias delictivas - como San La Muerte son asociados con el mal, pero ellos se consideran buenos. Me pregunto entonces: ¿qué hacen las personas con las clasificaciones que les son impuestas socialmente?

\section{Breves notas sobre La Tela y el trabajo de campo}

La Tela ${ }^{4}$ comparte características con otras villas y barrios empobrecidos de Argentina, esto es, la ilegalidad de los terrenos ocupados, las construcciones precarias en cartón, madera o ladrillo y la falta de servicios públicos, tales como alumbrado, agua corriente y cloacas. Comenzó a poblarse en los años setenta y fue incrementando su número de habitantes con las sucesivas crisis económicas entre los años noventa y comienzos del 2000. Se encuentra ubicada sobre la ruta 20, a la salida de Córdoba. Su nombre se debe a una tela de alambre que la separa de la Fábrica Militar de Aviones. A partir del 2016, comenzó un proceso de urbanización, impulsado por el estado provincial, a partir del cual instalaron alumbrado público y asfaltaron las calles, entre otras mejoras, por lo que pasó a llamarse barrio La Tela. La mayoría de los vecinos tiene trabajos informales en el sector de la construcción, en el servicio de limpieza o en la seguridad de las fábricas. Otros juntan papel, cartón y otros materiales en carros tirados por caballos, que luego venden o intercambian por alimentos. Algunos jóvenes,

4 El barrio Villa La Tela es un extenso asentamiento informal ubicado en el sudoeste de la ciudad de Córdoba. Con aproximadamente 15000 habitantes, es el más grande de la ciudad (NuestraCiudad.info 2017). 
especialmente varones, limpian vidrios de autos en el centro de la ciudad o en avenidas cercanas.

Llegué a la villa en marzo de 2009. En total fueron siete años de trabajo de campo con algunas etapas de mayor intensidad, hasta 2012, cuando empecé a ir casi todos los días. Asistía a eventos públicos como celebraciones del Día del Niño o reuniones vecinales y a veces me quedaba a dormir en las casas de los vecinos con quienes había desarrollado lazos de confianza y amistad. También participé de eventos familiares como bautismos, fiestas de cumpleaños y velorios. Me reunía con grupos de jóvenes en las esquinas y los acompañaba en sus actividades diarias, como limpiar vidrios, hacer denuncias en la comisaría o asistir a bailes de cuarteto ${ }^{5}$. Acompañé a familiares a hacer trámites en instituciones públicas, a la morgue, los visité en la cárcel, entre otras actividades.

Dicho trabajo de campo sustentó mis tesis de maestría y doctorado, en las cuales trabajé cuestiones relacionadas con la construcción local del miedo y el peligro. Consideraba relevante invertir el lente desde donde se estaba pensando el fenómeno de la inseguridad, siempre asociado con el delito y este vinculado con las zonas empobrecidas de la ciudad. En las últimas décadas, el problema social de la inseguridad se ha consolidado como preocupación en la agenda pública y política tanto nacional como provincial. La mayoría de las medidas implementadas se ha volcado a robustecer el accionar de las fuerzas represivas contra el delito. En Córdoba, este dato no es menor si se tiene en cuenta cómo se han venido recrudeciendo las políticas públicas de seguridad desde el año 2003 a partir de las medidas enmarcadas en el régimen de tolerancia cero (Hathazy 2014) que se relacionan, a su vez, con el fenómeno de la sobrecriminalización de sectores populares, especialmente de jóvenes varones (Font et al. 2015; Plaza y Semle 2010).

Así, la producción social de imágenes estigmatizantes sobre villas y barrios empobrecidos es un mecanismo que se ha profundizado en la arena pública (Guber 2007; Liberatori 2019; Puex 2003; Reguillo 2006). La vinculación poco complejizada entre pobreza y criminalidad produce ciertas desigualdades en relación con los derechos de las personas que habitan en villas y barrios empobrecidos (Cardoso de Oliveira 2008; Elbaum y Medeiros 2015). Asimismo, interfiere en sus actividades cotidianas, principalmente en aquellas que involucran salir de la villa. Por ejemplo, los jóvenes varones reciben constantes hostigamientos policiales cuando salen. Como he podido analizar, esta permanente sospecha de criminalidad les produce emociones como bronca y vergüenza, ya que la policía a menudo los humilla delante de los transeúntes que circulan por las calles de la

5 El cuarteto es un baile popular y tradicional de Córdoba. Su música es tocada en vivo por una banda y un cantante. 
ciudad (Fassin 2016; Liberatori 2014; Pita 2015). Por otro lado, la asociación entre pobreza y criminalidad obstaculiza la obtención de servicios como transporte escolar, telefonía o internet, puesto que muchas veces los prestadores se niegan a ingresar a la villa por miedo a ser robados.

Por tanto, abordar las moralidades construidas alrededor de la definición social de la figura del criminal, el delito y la inseguridad es imprescindible para analizar las múltiples maneras en que esos procesos de construcción de sentido se vuelcan luego en el recrudecimiento de políticas públicas destinadas a castigar criminales, considerados un mal social al que hay que combatir. Zaluar (1997), pensando en el caso brasileño, sostiene que la idea de sacrificar a aquellos agentes asociados con la malignidad como solución al problema de la violencia urbana proviene de una concepción moral. Estos agentes malignos son los criminales, quienes deben ser castigados en nombre del "bien”. Así, el mal y el bien se convierten en dos entidades absolutamente separadas para clasificar a las personas.

En la villa también me fue posible observar una configuración buenos/ malos, a través de la cual un grupo de vecinos se diferenciaba de otros a quienes acusaban de ser malos. Dichas acusaciones estaban fundadas en las trayectorias delictivas de los últimos, ya que estas reforzaban las imágenes sociales negativas que recaían sobre la villa, asociada con la inmoralidad, la suciedad y la ilegalidad (Guber 2007). El trabajo de campo prolongado y los lazos de confianza que estreché con diferentes vecinos me permitieron analizar un mecanismo social a través del cual las personas inspiraban miedo para conseguir respeto. Es decir, se hacían los malos para ser respetados por otros dentro y fuera de la villa. El respeto se obtenía a partir de saberes prácticos, poniendo el cuerpo y demostrando habilidades de lucha. En otras palabras, usaban la maldad como capital en un contexto socioeconómico en el cual escaseaban otros tipos de capital para desenvolverse, ser aceptados y reconocidos en el medio social (Bourgois 2010; Garriga Zucal 2007; Liberatori 2014, 2016; Previtali 2012). A su vez, pude analizar cómo el respeto no siempre se lograba a partir de la violencia física, sino también recurriendo a la posibilidad dual - para movilizar tanto el bien como el malde santos de moralidad ambigua, tales como San La Muerte. Esto me permitió descubrir los vínculos porosos entre el mal y el bien, las lógicas del respeto y las trayectorias delictivas. 


\section{Sissy y San La Muerte: una historia de amor y respeto}

Había escuchado hablar de Sissy muchas veces en La Tela, en oraciones del tipo "Necesito un $\mathrm{faso}^{6}$, me voy a lo de la Sissy", "Fulano no está, se fue a comprar a lo de la Sissy" o "Ayer hubo allanamiento en lo de la Sissy", por lo que si había algo que sabía de antemano de Sissy era que "vendía”. Esta fama le había costado la acusación moral de mala porque les vendía droga a los jóvenes de la villa. Para los vecinos de Sissy, con quienes tuve la oportunidad de conversar en reiteradas oportunidades, ella era una persona "muy complicada" que siempre tenía conflictos con los demás y con la policía. Otros tantos me advirtieron que "nada bueno podría sacar charlando con ella”.

Conocí a Sissy a fines de 2014 a través de Gastón, un chico con quien yo tenía una relación de confianza desde hacía muchos años. Gastón había acordado previamente con Sissy que "me llevaría” a hablar con ella porque yo estaba interesada en saber sobre San La Muerte. Ese día Gastón tenía que trabajar, así que me acompañó hasta su casa y se fue. Sissy ya me "había visto pasar" muchas veces con diferentes vecinos, pero nunca habíamos tenido la oportunidad de conversar. Entonces me invitó a su casa. Allí charlamos de cómo conoció al santo. Sucedió en la cárcel, cuando una compañera de pabellón le dio una estampita. Al principio, Sissy no creía en él, hasta que una noche — a modo de prueba- ella le pidió “que le hiciera soñar con su casa” porque no podía acordarse bien de cómo era. Ella me explicó que era a través de un pedido como se iniciaba una relación de reciprocidad ${ }^{7}$ con el santo. Gastón, en nuestras conversaciones sobre su experiencia con San La Muerte, me advirtió muchas veces nunca pedirle nada porque era así como iniciaba el culto.

Con aquel sueño, Sissy comenzó a relacionarse con San La Muerte. Sin embargo, para ella aquello fue más que un sueño. En sus palabras, esa noche "estuvo allí". La diferencia entre haber soñado y haber estado en la casa realmente es lo que dota de sentido el inicio de su devoción por el santo. Esa experiencia

$6 \quad$ Cigarrillo de marihuana.

7 Para comprender cómo se gesta la relación de San La Muerte con sus devotos, vale la pena mencionar debates clásicos en antropología sobre el don y la reciprocidad. Mientras que Mauss (1971) analiza los dones, Malinowski ([1926] 1998) se ocupa de la reciprocidad. Estos términos no dan cuenta de lo mismo exactamente. El don hace referencia a diferentes formas de intercambio y el de reciprocidad es un concepto más restringido, ya que refiere a un tipo específico de intercambio. Sin embargo, ambos conceptos intentan dar cuenta de que los intercambios están relacionados con la constitución de lazos sociales que generan obligaciones morales, cadenas de derechos y deberes, tal como sucede en el caso aquí estudiado. 
sobrenatural le permitió empezar a relacionarse con él, comprender su eficacia y obtener una validación de su existencia. Sissy me explicó que se dio cuenta de que aquello no fue un sueño por la nitidez de la experiencia vivida en cuanto a "la realidad" espacial de su vivienda. Esto es, si ella no se acordaba de cómo era su casa, tampoco hubiera podido soñar o lo hubiera hecho con cierto grado de distorsión respecto de los lugares “reales” y de la distribución de los espacios. Por otra parte, lo sucedido supone una jerarquización respecto de las experiencias: haber estado en su casa tiene más valor que haber soñado (Skartveit 2009). A partir de esa experiencia, Sissy comenzó a relacionarse con San La Muerte, quien la ha ayudado a atravesar circunstancias difíciles de su vida.

Una mañana de marzo de 2015 Sissy me contó que, cuando ella era muy pequeña, había quedado al cuidado de su padre tras la muerte de su madre:

Yo antes vivía en Villa Adela [un barrio aledaño a La Tela], con mi papá y mi hermano. Después mi papá se murió y me quedé con mi hermano que me golpeaba mucho y yo me cansé, y a los catorce años me junté con mi marido, el papá de mis hijos. (Entrevista, marzo de 2015)

También me dijo que antes su marido también la golpeaba, que una vez cuando estaba embarazada le había pegado tanto que casi pierde al bebé, que la engañaba con otras mujeres, pero que a partir de su estadía en la cárcel ella había aprendido a defenderse y, por consiguiente, su marido había aprendido a respetarla: "Nos llevamos mal, pero yo no quiero que se vaya por los chicos más chicos, pero ya no me pega, ahora me respeta”. Sissy describió la cárcel como un lugar que le había dado herramientas para "hacerse respetar”:

Y porque allá tenés que defenderte, a veces a alguna se le cruza algo y viene con un cuchillo y vos tenés que pelear. Y así yo aprendí a hacerme respetar y cuando salí le dije a mi marido: "Vos no me volvés a pegar nunca más porque yo te mato y con tu sangre voy a lavar la estatua del santo”. Una vez lo agarré a los cuchillazos y así es como ahora me respeta y respeta a mi santito porque le tiene miedo. (Entrevista, julio de 2015)

El santo se gana el respeto porque, además de su rapidez y eficacia para cumplir los pedidos, tiene la posibilidad de hacer el mal, de causar daño a quien le incumple las promesas, a los enemigos de sus devotos. Sissy me ha contado que sus vecinos le tienen miedo a San La Muerte y que le han advertido muchas veces que tenga cuidado, "que me puede matar a mis nietos, porque, si se enoja, él puede llevarse lo que vos más querés”.

Así, Sissy y otras personas con las que he conversado coinciden en que el santo "se hace respetar". Si alguien le pide un favor y este cumple, hay que devolverlo efectuando lo prometido en el tiempo estipulado. Una vez, mientras Sissy 
limpiaba cuidadosamente las estatuas del santo que tiene distribuidas en su casa y la gruta que tiene afuera en el patio, me comentaba:

San La Muerte se hace respetar. O sea, vos por ejemplo a la Virgen le podés prometer ir hasta la gruta de Alta Gracia ${ }^{8}$ y después, si no podés cumplir, le prendés una velita y ya está. Pero a San La Muerte no, a él le tenés que cumplir sí o sí, porque si no, te puede venir el mal. (Conversación con Sissy e Iván, marzo de 2015)

Desde la mirada de Sissy, San La Muerte difiere de la figura de un dios bondadoso, carente de impureza y ambigüedad. El poder del santo radica justamente en esa ambivalencia entre el mal y el bien, en la posibilidad de amar y castigar devolviendo el mal. Meintjes (2017) trabaja la ambigüedad estética en relación con una danza y canción del pueblo zulú en Sudáfrica y analiza los espacios inciertos y las posibilidades que deja abiertas dicha ambigüedad, mostrando cómo la danza brinda un mapa de los límites entre lo que puede y no decirse, entre lo permitido y lo controversial. Para esta autora, la ambigüedad contribuye a expresar con un velo de ilegibilidad aquello que no puede ser dicho y que revela cuestiones políticas.

San La Muerte permite también la ambigüedad en sus devotos, ya que estos pueden pedirle ayuda en asuntos ilegales, por ejemplo. El santo posibilita explicitar aquellas cosas que no podrían ser dichas a un santo común y moralmente identificado con el bien. Así, la indefinición moral de santos como San La Muerte admite la cercanía de personas que se consideran buenas, pero que son señaladas como malas.

Yo lo amo a él. Él me conoce a mí, él sabe que yo soy buena, aunque tengo mis actividades, pero es para ayudar a mi familia. Yo a él le tengo confianza y le puedo pedir que me venga un cliente. Le prendo una velita y ahí nomás aparece alguien a comprarme un faso, una alita . En cambio, a Dios yo no le puedo pedir esas cosas. (Entrevista con Sissy, julio de 2015)

Desde que Sissy conoció a San la Muerte comenzó a sentirse protegida y comprendida. Calzato (2008) y Flores Martos (2014) reflexionan sobre cómo los santos populares se convierten en una alternativa para las personas de sectores

8 Es una tradición para los fieles católicos de la Virgen de Lourdes caminar en procesión hasta Alta Gracia, ciudad ubicada a unos 35 kilómetros del centro de Córdoba, y visitar una gruta en donde las personas realizan pedidos y rezos. accesible y su efecto es similar al de la cocaína, pero se necesita menos cantidad, por lo que es una de las preferidas de las personas que la consumen en la villa. 
vulnerables frente a otros cultos oficiales, como el catolicismo o el evangelismo. Pero también, en ocasiones, se vuelven una opción para enfrentar las vicisitudes de la precariedad material de la vida, distinta de las ofrecidas por las instituciones estatales y otras vías convencionales. En relación con este punto, algunos autores señalan las incompetencias del Estado para solventar las cuestiones básicas demandadas por la gente. Míguez (2012) ha trabajado sobre cómo la religiosidad de los sectores populares ha ido cambiando conforme fueron mutando las condiciones estructurales, para poder acomodarse a estas. Analiza cómo los nuevos cultos se han convertido en alternativas morales que aceptan estilos de vida más plurales, incluso aquellos relacionados con el delito. Por consiguiente, las respuestas de las personas no son mecánicas ni mucho menos pasivas frente a las estructuras sociales y religiosas.

En vinculación, Semán (2001), Carozzi $(2005,2006)$ y Martín (2007) plantean que, en un primer momento, los trabajos sobre religiosidad popular propusieron que esta última es una forma de resistir las situaciones de dominación, tanto frente al catolicismo como a las clases sociales más acomodadas. Así, santos populares como San La Muerte, Gauchito Gil, María Lionza y divinidades de religiones afrobrasileñas, entre otros, se han erigido como una forma de revancha simbólica de los pobres o de desnaturalización del orden social por parte de los sectores populares (Carozzi 2006, 99). En este sentido, los autores explican, por ejemplo, cómo las leyendas sobre canonizaciones populares retrataban a los santos como seres cuyas biografías se encontraban fuera de la ley. Sin embargo, también advierten que el concepto de resistencia puede anular la agencia de las personas y de sus cultos, puesto que no es posible tomarlos solamente como residuales de la cultura dominante. Bajo este argumento, Semán (2001) plantea que hay que pensar las religiosidades populares "en su capacidad creadora" y que estas se caracterizan por una "visión cosmológica" que trasciende la institucionalidad de las religiones oficiales y que debe entenderse en el marco de la vida cotidiana de los individuos. Así, Sissy construye con San La Muerte una relación de amor y cuidados cotidianos mutuos.

"Los lunes yo lo atiendo al Santo, es su día, por decir. Le limpio la gruta, le prendo cigarrillos, alguna velita, le pongo una botella de whisky”. La gruta debe permanecer tapada por una cuestión de "privacidad y respeto" del santo:

Para mí, él es uno más de mi familia, yo le tengo un amor de madre. Cuando los domingos almorzamos acá en el patio, yo lo destapo al santito, así come con nosotros. Y por las mañanas, yo también lo destapo para que le entre el sol y para que me cuide la casa cuando salgo. (Entrevista, julio de 2015) 
Figura 2. Gruta del santo en el patio de la casa de Sissy

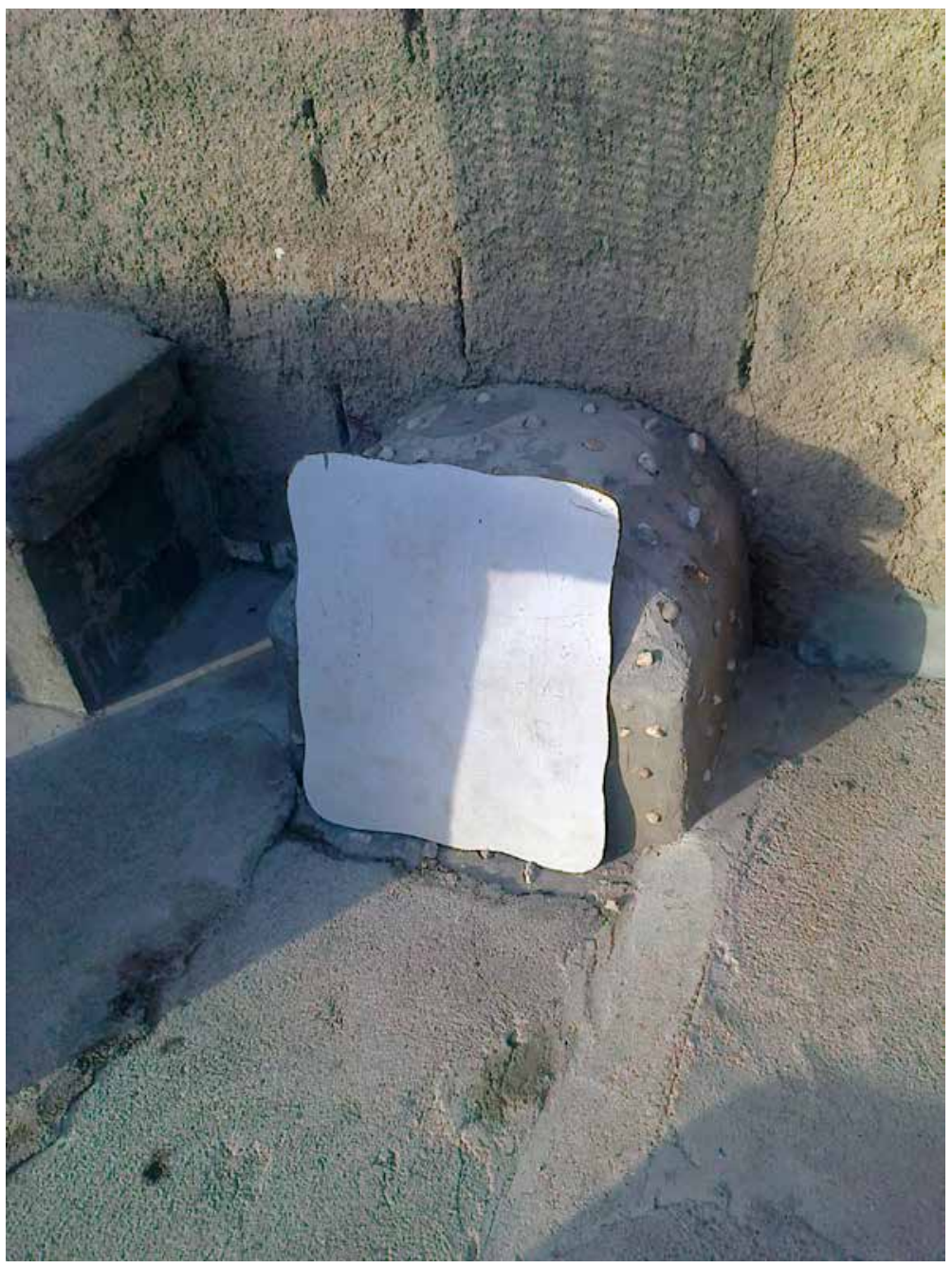

Fuente: fotografía de la autora, 2015.

Sissy ha establecido con San La Muerte una relación cotidiana de cuidados y favores mutuos:

—Él me protege siempre. Una vez me avisó que venía la policía.

- ¿Cómo te avisó?

- Se cayó una estatua que tengo en el mueble de la entrada, ¿viste? Es imposible que esa estatua se cayera sola porque no le da el viento ni nada. Un día vino mi hija corriendo y me dijo que se había caído, y entonces yo supe que algo estaba pasando, que algo andaba mal. Entonces 
saqué la mercadería y la llevé a lo de una vecina y ella me dijo que andaba la policía haciendo allanamiento. Yo le pedí al flaquito, como a veces le digo, que todo fuera tranquilo, que no pasara nada. Al rato, entraron a mi casa y no encontraron nada. (Entrevista, julio de 2015)

Como vimos, Sissy sabe que a San La Muerte puede pedirle cosas ilegales y que dicho pedido será escuchado sin juicios, porque con él tiene una relación de familiaridad y de amor. Como ella ha expresado, es buena a pesar de sus actividades, cuya justificación moral recae en que las realiza por el bien de su familia y no para beneficio personal. Lo colectivo por sobre lo individual es una característica de bondad que muchas veces he escuchado de los vecinos en la villa para diferenciar a los buenos de los malos. Por ejemplo, aunque es sabido que robar es malo y es un delito, es moralmente justificable si se realiza para ayudar a la familia.

Por otro lado, podemos observar que, a pesar de la ambigüedad del santo que asusta a los vecinos y a su marido, Sissy le tiene confianza porque él tiene la posibilidad de empoderarla. Entonces, más allá de cumplirle promesas, protegerla, brindarle comprensión y contención, San La Muerte es capaz de darle poder para que ella misma se defienda de los malos tratos de su marido, de la mirada negativa de sus vecinos, para que atienda sus negocios y evite el peligro en los allanamientos. Como muestra el trabajo de Ortner (2009) con los sherpas en Nepal, los sujetos siempre tienen poder, aunque dependan de los dioses para que los protejan de la maldad que otros pueden proporcionarles. Ese poder puede traducirse en agencia en la medida en que los humanos, a través de las ofrendas, usan el poder de los dioses a su favor: "Sin someterse al poder ni resistirlo en una acepción simple, los sherpas trabajan a través suyo y lo viran hacia sus propósitos” (Ortner 2009, 33). Asimismo, el poder de los dioses no es una propiedad intrínseca ni absoluta de ellos, sino que es producido, justamente, por el trabajo religioso de los devotos. De igual manera, es a partir de la relación de reciprocidad que se construye entre Sissy y San La Muerte como ambos pueden empoderarse para hacerse respetar.

\section{Iván y la gruta del santo}

A Iván le regalaron una estampita del santito cuando estaba en la cárcel y fue allí donde se le apareció por primera vez:

Estaban todos durmiendo y yo me desperté al medio de la noche, eran como las cuatro de la mañana y lo vi, empecé a gritar y nadie se 
despertaba y entonces él me dijo: "No grites, soy yo, vengo para ayudarte a que cambies de vida, ya no podés seguir así”. Y yo, gracias a él, cambié mucho. Vos no sabés lo que era yo antes, mi vida era un desastre, siempre fue así. Desde que era chico, mi papá era alcohólico y le vivía pegando a mi mamá. Éramos ocho hermanos, pasábamos hambre y yo me cansé de ver cómo le pegaban a mi vieja. Una vez, a los once años, le hicimos frente a mi papá y nos pegó tanto que del miedo nos escondimos debajo de la cama. Y después se separaron y nosotros nos vinimos acá a La Tela con mi mamá y mi papá se quedó en Las Violetas, donde vivíamos antes, con otra mujer. Y, bueno, digamos que a los once años yo me puse los pantalones de hombre y dejé la escuela. Yo quería ayudarla a mi mamá y, bueno, empecé a robar y también a drogarme. [...] Yo gracias al santo cambié mucho; yo me sigo drogando, no te voy a decir que no, pero solo fumo porro, antes me drogaba con ácido, pastillas, de todo. (Entrevista, julio de 2015)

Esto me contaba Iván una tarde de julio de 2015, sentados al costado de la gruta que había montado al frente de su casa, en la que vivía con sus suegros, sus cuñados, su novia y su hijo de un año y medio. Hacía mucho frío; el viento helado nos pegaba en las mejillas. Era la tercera vez que nos veíamos, pero la primera que nos sentábamos a conversar. Otras tantas veces habíamos intentado coordinar para charlar, pero sus horarios de trabajo en una panadería de un barrio aledaño a La Tela complicaban nuestro encuentro. Salía muy temprano en la madrugada y regresaba al anochecer. Entonces fui conociendo a su familia gracias a una vecina que me presentó a su suegra. Casi siempre que iba, era Marcela quien me recibía y me contaba las historias que sucedían por las noches alrededor de la gruta que el Loco — como le decía a su yerno- había hecho al santo y por la cual “los vecinos se quejaban”. “¡Y de qué se quejan los vecinos?”, le pregunté a Marcela. "Y... de que en la cuadra, desde que está la gruta, pasan cosas raras...”.

Esa tarde, Iván destapó la gruta y me mostró cómo era por dentro: tenía dos estampitas y dos estatuas pequeñas de San La Muerte y una lámina de Gauchito Gil. Según me han explicado las personas con quienes conversé en La Tela, devotas del primero, ambos santos eran amigos. Más aun, en esa estampita de la gruta de Iván, San La Muerte está bendiciendo a Gauchito Gil. Según me explicó:

San La Muerte era un cura que vivía en Corrientes y le quitaba a los ricos para dar de comer a los pobres, igual que Gauchito Gil. Un día lo metieron preso porque lo acusaron de matar a unos hombres y se suicidó en la cárcel, pero él no había sido, entonces juró vengarse de la policía [...]. Yo creo que por todo eso que él sufrió puede entender tanto y ayudar a los que creemos en él. (Conversación con Iván, julio de 2015) 
Figura 3. Gruta de Iván destapada

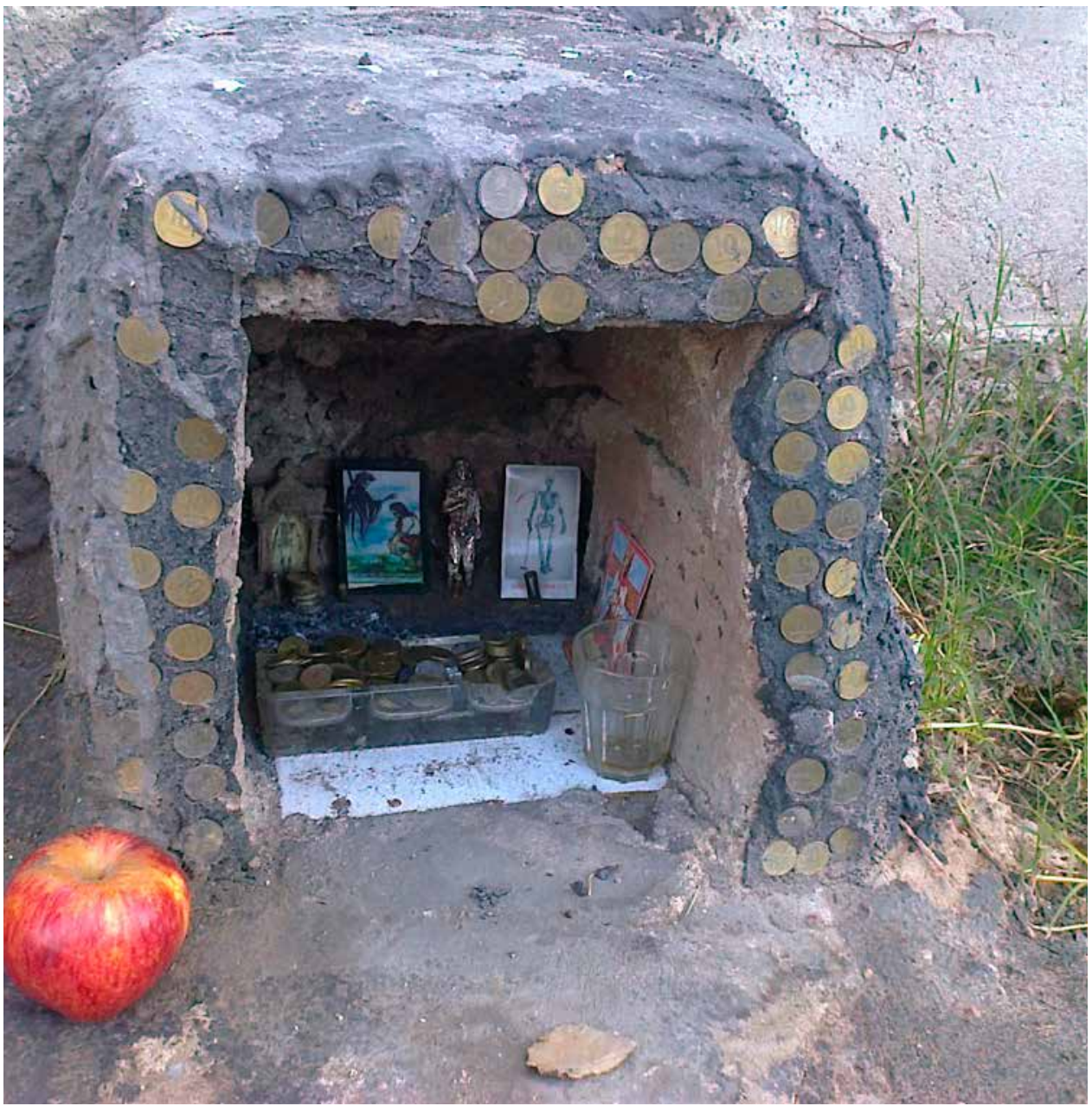

Fuente: fotografía de la autora, 2015.

Iván y yo pudimos conversar largamente otras tres veces más sobre el santo y la gruta. Me explicaba que San La Muerte era muy poderoso porque "todo lo que le pedís te lo cumple”, sin importar si el pedido está relacionado con el bien o el mal:

yo le pido solo para bien, por mi hijo, por la salud de mi familia, pero también se le puede pedir por el mal. Pero si le pedís por el mal, el daño te vuelve; si le pedís por el bien, te vuelve el bien. Yo le pedí trabajo y a la semana conseguí este de la panadería [...] Lo que le ponés en la gruta tiene que ver con lo que vos querés que te dé. Yo cuando tengo plata le pongo whisky, le pongo comida; ahora esta manzana para que coma. 
En verdad no se le pone plata, pero yo le pongo esta bandejita para irle juntando monedas para comprarle cigarrillos. Algunos le ponen droga, merca, fasos, pero yo no le pongo porque lo que le ponés te vuelve y yo no quiero que me vuelva droga, yo quiero trabajo y plata; por eso, le pegué esas moneditas alrededor de la gruta. (Entrevista, julio de 2015)

San La Muerte no juzga a sus devotos ni los pedidos que le hacen, simplemente los cumple. Por tanto, como expresa Iván, hay que ser cuidadosos y conscientes a la hora de pedir porque el santo es efectivo $y$, además, lo que uno le pide, le vuelve. Al igual que Sissy, Iván atribuye a su vida relacionada con la delincuencia y las drogas las desventuras tempranas de su vida familiar de origen, signada por la violencia, la pobreza y la adicción de su padre al alcohol. Tal cual las vidas de Iván y Sissy, el santo tuvo que pasar sufrimientos y cayó en la cárcel, donde murió jurando vengarse de quienes injustamente lo habían detenido. Por tanto, le es posible comprender el sufrimiento de estos devotos, a quienes se les apareció cuando atravesaban dificultades mientras estaban presos. También le resulta posible comprender sin juzgar sus actividades delictivas, en cuanto estas son medios que sirven a fines colectivos, como ayudar a la familia. Su diferencia con cualquier otro santo de religiones más tradicionales, como la católica o la evangélica, es que posee una moralidad más extensa o ambigua que abarca contextos más diversos e inclusivos (Míguez 2012).

Martín (2007) propone que la categoría de religiosidad popular con la que se ha intentado reemplazar la de religión presenta ciertos problemas. Esta autora entiende que parte de la dificultad del concepto es que no es utilizado por las personas con quienes trabajamos y que, además, es demasiado amplio para poder analizar casos concretos. En cambio, afirma que pensar en prácticas de sacralización nos permite observar el mundo habitado de esas personas, desplazándonos del paradigma modernocéntrico de secularización. Entonces, es fundamental conocer en profundidad cuál es ese mundo habitado para poder comprender cómo las prácticas espirituales regulan la vida cotidiana de los sujetos, configuran sus moralidades y dan sentido a su mundo (Carozzi 2006; Ceriani 2013).

En este sentido, San La Muerte es más acorde con los valores morales de Iván, quien sabe que no es correcto robar o drogarse, pero le puede pedir ayuda al santo sin dejar de ser lo que es. En otras palabras, este lo acepta con todos sus defectos y sufrimientos, comprende la vida de los que han atravesado dificultades y, por tanto, el sentido de sus acciones, aunque estas no se ajusten a los valores morales que marca la sociedad. Es justamente desde la aceptación de su propia vida y de su propio ser que el santo se dispone a ayudar a sus devotos; no les exige que cambien para acercarse a él, no los juzga por su "maldad”, porque 
su sentido del mal es más laxo que el de otros santos. Los acepta tal cual son y les extiende la mano. San La Muerte, al igual que los devotos aquí consultados, ha incurrido en prácticas delictivas al robarles a quienes más tienen para repartir la riqueza entre los más pobres, y es considerado como un santo peligroso o malo por otros vecinos de La Tela. Incluso es temido por aquellos que se quejan de la gruta de Iván porque “pasan cosas raras”.

Me pregunto: ¿cómo podemos pensar en los sentidos sobre el mal y el bien que construyen las personas sin analizar la resistencia frente a un orden que establece y significa cuál es uno y cuál es otro, dejando a personas como Iván del lado menos favorecido? Como vimos, Iván y Sissy son acusados de “malos” por otros vecinos en La Tela porque, con sus “prácticas delictivas”, perjudican a los vecinos que se consideran "buenos" y refuerzan la imagen social negativa que recae sobre las villas y sus habitantes. Ortner (1995) afirma que la resistencia es una oposición a la dominación de un poder que se encuentra institucionalizado. Esta autora propone que no debe analizarse la cuestión de las resistencias sin tener en cuenta las muchas diferencias que caracterizan a los subordinados, incluso dentro de un mismo grupo, esto es, de género, edad, trayectorias biográficas, posiciones sociales, etc. Por tanto, también señala la necesidad de volver a los estudios etnográficos para analizar las particularidades que adquieren los distintos modos de resistencia, aunque no necesariamente las personas se refieran a ella. A partir de un lúcido “zigzagueo entre Geertz y Foucault”, Ortner (2009) construye la categoría de resistencia densa para analizar casos microscópicos sin perder de vista las estructuras a las que las personas resisten. Porque esas cuestiones de gran escala permean las vidas de las personas, sus representaciones y las prácticas a partir de las cuales dan sentido al mundo. Así, podemos plantear que San La Muerte se vuelve para Iván y Sissy una posibilidad de resistir las acusaciones de maldad que reciben de sus vecinos y, a su vez, una alternativa para sobrellevar la vida en un lugar socialmente estigmatizado y atravesar las dificultades económicas incurriendo en prácticas delictivas.

\section{La gruta y los vecinos}

En el mes de julio de 2015 comencé a entrevistar a diferentes vecinos que vivían en la manzana donde estaba ubicada la gruta de Iván. Angy, una vecina de unos sesenta años que vivía junto a la casa de Iván, me decía: 
a mí me da miedo ese santo porque es el santo de los que chorean $^{10}$, él los protege. Hace poco un chico que se junta ahí en la gruta cayó preso, los amigos le hicieron una promesa al santo y al otro día ya lo soltaron. (Entrevista, abril de 2015)

Isabel, una mujer de unos treinta años que vivía a dos casas de donde estaba ubicada la gruta, comentaba:

A mí me da miedo esa gruta. Desde que está ahí, la cuadra se llenó de gatos que antes no había y eso es una señal del diablo. Una vez vi unas sombras y escuché unos ruidos y, cuando salí, no había nada ni nadie. (Entrevista, mayo de 2015)

Eduardo, otro vecino de unos cuarenta años que vivía en el mismo sector de Iván, me explicaba:

Dicen que ese santo es el diablo. Y ese con el que vos estabas hablando el otro día [se refiere a Iván] es un caradura, ha tenido problemas con todos los vecinos, hasta con su propia familia. Viven drogándose ahí con los amigos alrededor del santo ese y a veces andan a los tiros. [...] Pero a mí no me da miedo, es un santo de la gente ignorante, yo creo en Dios. (Entrevista, abril de 2015)

San La Muerte es asociado con el diablo, el mal y la delincuencia, por lo que tiene mala fama en Villa La Tela. Sin embargo, esa fama no solo está vinculada con la maldad y el peligro, sino además con la "gente ignorante”. En varias oportunidades, vecinos como Eduardo se han referido a la familia de Iván como “campesinos” e "ignorantes” porque son oriundos del interior de Córdoba. Martín (2005) y Semán (2001) plantean que, en general, se tiende a señalar a los sectores populares y campesinos como "atrasados" e "ignorantes” y las "creencias" en santos populares refuerzan esta valoración, contraria a las ideas de modernidad y progreso arraigadas en las clases más acomodadas. San La Muerte es un santo “popular”, no es aceptado por la Iglesia católica como tal y además está vinculado a estigmas de los cuales muchos de los vecinos de Villa La Tela intentan alejarse, aunque la mayoría de ellos proviene del interior del país o de pueblos serranos.

Svampa (2010) analiza cómo la nación argentina se ha constituido sobre la base de la oposición civilización/barbarie que se ha manifestado en diferentes momentos de la historia, en los cuales diversas personas se han asociado con uno u otro calificativo. Para la autora, este proceso de clasificación de los sujetos involucra prejuicios raciales y sociales cargados de dicho dilema. Para Svampa, la

10 Categoría nativa de Córdoba que significa "robar", así como choro es "ladrón". 
imagen actual de peligrosidad, asociada con lo bárbaro y con el desorden social, se encuentra representada por las poblaciones "pobres y movilizadas”. Aunque considero que los juegos de oposición son porosos y, en la práctica, no se manifiestan de manera extrema en la vida cotidiana de las personas, esta autora propone una herramienta analítica valiosa para pensar cómo el dilema civilización/barbarie permea los sentidos sobre el mal y el bien y las moralidades que se construyen en la villa y cómo son vividos por los propios vecinos de La Tela (Quirós 2006, 2014).

\section{Palabras finales}

A lo largo del texto vimos cómo las relaciones que construyeron Sissy e Iván con San La Muerte los empoderaban para enfrentar las dificultades de su vida cotidiana y las acusaciones de maldad realizadas por los vecinos de la villa. El santo los ayudaba a defenderse de los malos tratos provenientes de personas allegadas, así como también los protegía de diversos males, como el sufrimiento o los problemas relacionados con la ilegalidad de sus actividades. San La Muerte, a diferencia de Dios, podía comprenderlos en la totalidad de su ser. Los aceptaba incluso con sus sufrimientos y maldades. Más aún, colaboraba con ellos, aunque sus pedidos estuvieran vinculados con cuestiones ilegales. Esto en virtud de cierta identificación entre San La Muerte y sus devotos. Al igual que el santo, Sissy e Iván atravesaron situaciones dolorosas en sus vidas - signadas por la pobreza, la violencia y la cárcel一, no solamente en el aspecto personal, sino también en sus vivencias colectivas en la villa —estigmatizada socialmente y relacionada con el delito, la inseguridad y la inmoralidad-.

A su vez, en ambos casos, San La Muerte se apareció cuando sus devotos estaban presos a causa de estar inmersos en prácticas delictivas como el robo, la venta y el consumo de drogas. Los dos tuvieron un contacto cercano con él: Sissy a partir de un sueño vívido; Iván mediante una aparición. Esos dos eventos signaron la relación de reciprocidad, amor, respeto y protección entre estos vecinos de La Tela y el santo. Por otra parte, según relató Iván, el santo también atravesó el encierro porque fue injustamente condenado por un crimen que no había cometido. Este punto de encuentro entre la trayectoria biográfica de San La Muerte y la de sus devotos explica por qué esta figura comprende los sentidos de transitar por establecimientos penitenciarios, estar alejados de sus hogares y en contextos de violencia en donde hay que aprender a defenderse y hacerse respetar. Como vimos, el respeto es una condición necesaria para atravesar contextos hostiles 
tanto en la villa como en la cárcel. Por eso, el santo se hace respetar y es muy severo con la falta en las promesas que le hacen. A diferencia de otros santos o de la Virgen, que pueden “comprender” si un devoto no logra cumplir lo prometido, San La Muerte exige suma eficacia, así como él es rápido y eficaz para realizar los favores que le solicitan. Como vimos, el respeto es inherente a la relación que establece con sus devotos. Dado que él los respeta tal cual son, así mismo exige que se respeten los acuerdos. Es desde ese lugar de aceptación, comprensión y respeto que San La Muerte ayuda a las personas que le rinden culto y les proporciona condiciones favorables para que puedan "cambiar de vida”.

En estas páginas pudimos analizar cómo las experiencias espirituales de Sissy e Iván con San La Muerte movilizaban valores morales con los cuales los vecinos de Villa La Tela clasificaban a las personas y delimitaban fronteras entre el bien y el mal. Sin embargo, vimos cómo por momentos las fronteras se volvían porosas y era en esos grises donde encontrábamos que la maldad, aunque estaba asociada a quienes se encontraban vinculados con prácticas moralmente dudosas o ilegales, podía hacerse extensiva a todos los vecinos de La Tela, en cuanto habitantes de un lugar sobre el cual recaía una imagen social negativa y prejuiciosa. De esta manera, el mal se convertía en una posibilidad que las personas podían movilizar, entre otras cosas, para mantener y obtener respeto tanto dentro como fuera de la villa y resistir las condiciones de un orden social que los ubicaba siempre del lado de lo abyecto y los responsabilizaba de los males sociales, tales como la inseguridad. Por tanto, el título de este artículo, que tomé prestado de El Soldado, una banda de rock argentina, intenta reflejar cómo las personas que habitan las zonas desfavorecidas de la ciudad pueden convertirse metafóricamente en doblemente perdedores: por un lado, como habitantes de una villa a quienes se les niega la obtención de derechos básicos y, por otro, al ser juzgados por sus propios vecinos, quienes los responsabilizan de reproducir los estigmas sobre el lugar donde viven. Así, San La Muerte termina siendo el ángel al que pueden acudir con la certeza de que serán comprendidos.

\section{Referencias}

Bourgois, Philippe. 2010. En busca de respeto: vendiendo crack en Harlem. Buenos Aires: Siglo XXI.

Calzato, Walter Alberto. 2008. "San La Muerte (Argentina). Devoción y existencia. Entre los dioses y el abandono”. LiminaR. Estudios Sociales y Humanísticos 6 (1): 26-39. https://doi. org/10.29043/liminar.v6i1.264 
Canals, Roger. 2012. “¿Más allá del dualismo? Reflexiones sobre la noción de 'cuerpo’ en el culto a María Lionza (Venezuela)”. Revista de Dialectología y Tradiciones Populares 23: 136-193. https://doi.org/10.1590/S0102-69092008000200010

Cardoso de Oliveira, Luis Roberto. 2008. “Existe violência sem agressão moral?”. Revista Brasileira de Ciências Sociais 23 (67): 135-146. https://doi.org/10.1590/S010269092008000200010

Carozzi, María Julia. 2005. "Revisitando La Difunta Correa: nuevas perspectivas en el estudio de las canonizaciones populares en el Cono Sur de América”. Revista de Investigaciones Folclóricas 20: 13-21. http://www.diversidadreligiosa.com.ar/wp-content/uploads/2013/04/ Carozzi_Difunta_Correa.pdf

-. 2006. "Antiguos difuntos y difuntos nuevos. Las canonizaciones populares en la década del 90”. En Entre santos, cumbias y piquetes: las culturas populares en la Argentina reciente, compilado por Daniel Míguez y Pablo Semán, 97-110. Buenos Aires: Biblos.

Ceriani, César. 2013. "La religión como categoría social: encrucijadas semánticas y pragmáticas”. Cultura y Religión 7 (1): 10-29. https://ri.conicet.gov.ar/handle/11336/3847

Chumbita, Hugo. 2013. Jinetes rebeldes: historia del bandolerismo social en la Argentina. Buenos Aires: Colihue.

Cozzi, Eugenia, Enrique Font y María E. Mistura. 2014. "Desprotegidos y sobrecriminalizados: interacciones entre jóvenes de sectores populares, policía provincial y una fuerza de seguridad nacional en un barrio de la ciudad de Rosario”. Derechos Humanos 8: 3-30. http://www.saij.gob.ar/eugenia-cozzi-desprotegidos-sobrecriminalizados-interaccionesentre-jovenes-sectores-populares-policia-provincial-una-fuerza-seguridad-nacional-barrio-ciudad-rosario-dacf150281-2014-12/123456789-0abc-defg1820-51fcanirtcod

Elbaum, Lucía y Flavia Medeiros. 2015. “Quando existe 'violência policial’? Direitos, moralidades e ordem pública no Rio de Janeiro”. Dilemas: Revista de Estudos de Conflito e Controle Social 8 (3): 407-428. https://revistas.ufrj.br/index.php/dilemas/article/view/7299

Fassin, Didier. 2016. La fuerza del orden: una etnografía del accionar policial en las periferias urbanas. Buenos Aires: Siglo XXI.

Favret-Saada, Jeanne. 2005. "Ser afetado". Traducido por Paula Siqueira. Cadernos de Campo, 13: 155-161. https://doi.org/10.11606/issn.2316-9133.v13i13p155-161

Flores Martos, Juan Antonio. 2014. "Iconografías emergentes y muertes patrimonializadas en América Latina: Santa Muerte, muertos milagrosos y muertos adoptados”. AIBR: Revista de Antropología Iberoamericana 9 (2): 116-140. https://recyt.fecyt.es/index.php/AIBR/ article/view/32808

Garriga Zucal, José. 2007. "Haciendo amigos a las piñas”: violencias y redes sociales de una hinchada de fútbol. Buenos Aires: Prometeo.

Goldman, Marcio. 2003. "Os tambores dos mortos e os tambores dos vivos. Etnografia, antropologia e política em Ilheus, Bahia. São Paulo”. Revista de Antropologia 46 (2): 445-476. https://www.scielo.br/pdf/ra/v46n2/a12v46n2.pdf 
-. 2006. "Alteridade e experiência: antropologia e teoria etnográfica”. Etnográfica 10 (1): 161-173.http://www.scielo.mec.pt/scielo.php?script=sci_abstract\&pid=S0873-65612006000 $100008 \& \operatorname{lng}=$ es $\&$ nrm $=$ iso\&tlng $=\mathrm{pt}$

Guber, Rosana. 2007. "Identidad social villera". En Constructores de otredad: una introducción a la antropología social y cultural, organizado por Mauricio Boivin, Ana Rosato y Victoria Arribas, 151-166. Buenos Aires: Antropofagia.

Hathazy, Paul. 2014. "Inseguridades interpeladas. Políticas contra el crimen y ciudadanías en la Córdoba neoliberal”. En Merodear la ciudad: miradas antropológicas sobre espacio urbano e "inseguridad" en Córdoba, organizado por Natalia Bermúdez y Malena Previtali, 27-55. Córdoba: Idacor; UNC.

Liberatori, Marina. 2014. "Y sí, vivo en una villa. Una etnografía sobre los miedos y peligros en Villa La Tela (Córdoba)”. Tesis de Maestría en Antropología, Facultad de Filosofía y Humanidades, Universidad Nacional de Córdoba, Córdoba.

—. 2016. "El mal que puede volver. Antropología de los sentidos sobre el mal, experiencias con santos populares y relaciones sociales en Villa La Tela (Córdoba)”. Tesis de Doctorado en Ciencias Antropológicas, Facultad de Filosofía y Humanidades, Universidad Nacional de Córdoba, Córdoba.

—. 2019. "Las ambigüedades del miedo: un análisis etnográfico sobre inseguridades en una villa de Córdoba, Argentina”. Revista Etnográfica 23 (1): 22-47. https://doi.org/10.4000/etnografica.6255

Malinowski, Bronislaw. (1926) 1998. Los argonautas del Pacífico occidental. Barcelona: Planeta DeAgostini.

Martín, Eloísa. 2007. "Aportes al concepto de religiosidad popular: una revisión de la bibliografía argentina de los últimos veinticinco años”. En Ciencias sociales y religión en América Latina, coordinado por María Julia Carozzi y César Ceriani Cernadas, 30-54. Buenos Aires: Biblos.

Mauss, Marcel. 1971. Sociología y antropología. Madrid: Tecnos.

-. 2010. Ensayo sobre el don: forma y función del intercambio en las sociedades arcaicas. Madrid: Katz.

Meintjes, Louise. 2017. Dust of the Zulu: Ngoma aesthetics after apartheid. Carolina del Norte: Duke University Press.

Míguez, Daniel. 2008. Delito y cultura. Los códigos de la ilegalidad en la juventud marginal urbana. Buenos Aires: Biblos.

-. 2012. "Canonizaciones y moralidades en contextos de pobreza urbana. Las lógicas del orden y la transgresión en la Argentina de fines del siglo XX”. Cultura y Religión 6 (1): 241-274. https://www.revistaculturayreligion.cl/index.php/culturayreligion/article/view/60

NuestraCiudad.info. 2017. "Barrio Villa La Tela”. https://nuestraciudad.info/portal/Villa_ La_Tela.C\%C3\%B3rdoba.CBA

Ortner, Sherry. 1995. Resistance and the problem of ethnographic refusal. Cambridge: Cambridge University Press. 
-. 2009. Resistencia densa: muerte y construcción cultural de agencia en el montañismo himalayo. Buenos Aires: Idaes; Universidad Nacional de San Martín.

Pita, María Victoria. 2015. "Seguridad ciudadana y acceso a la justicia: la gestión y los dilemas de las conflictividades locales”. Ponencia presentada en el IX Encuentro de la Red Latinoamericana de Antropología Jurídica (Relaju), Pirenópolis Goiás, 30 de septiembre -2 de octubre.

Plaza Schaefer, Valeria y Pablo Semle. 2010. Seguridady política criminal desde la perspectiva de los derechos humanos. Córdoba: UNC.

Previtali, María Elena. 2012. Andar en la calle y rescatarse: una etnografía sobre jóvenes, familias y violencias en Villa El Nailon, Córdoba. Madrid: Editorial Académica Española.

Puex, Nathalie. 2003. "Las formas de la violencia en tiempos de crisis: una villa miseria en el conurbano bonaerense”. En Heridas urbanas: violencia delictiva y transformaciones sociales en los noventa, editado por Alejandro Isla y Daniel Míguez, 35-70. Buenos Aires: Editorial de las Ciencias.

Quirós, Julieta. 2006. Cruzando la Sarmiento: una etnografía sobre piqueteros en la trama social del sur del Gran Buenos Aires. Buenos Aires: Antropofagia.

-. 2014. "Etnografiar mundos vívidos. Desafíos de trabajo de campo, escritura y enseñanza en antropología”. Publicar en Antropología y Ciencias Sociales 17: 47-65. http://ppct.caicyt. gov.ar/index.php/publicar/article/view/4914

Reguillo, Rosana. 2006. "Los miedos: sus laberintos, sus monstruos, sus conjuros. Una lectura socioantropológica”. Etnografías Contemporáneas 2: 54-75.

Semán, Pablo. 2001. "Cosmológica, holista y relacional: una corriente de la religiosidad popular contemporánea”. Ciencias Sociales y Religión 3: 45-74. https://doi.org/10.22456/19822650.2169

Skartveit, Hanna. 2009. Ángeles populares: la formación socialy espiritual de Gilda y Rodrigo. Buenos Aires: Idaes; Universidad Nacional de San Martín.

Svampa, Maristella. 2010. “Civilización o barbarie: de 'dispositivo de legitimación’ a 'gran relato”. Ponencia presentada en el seminario “200 años de historia argentina el difícil proceso de construcción de una nación”, Centro Haroldo Conti, Ciudad de Buenos Aires, 12-14 de mayo.

Zaluar, Alba. 1997. “O crime e a não-cidadania: os males do Brasil são”. En O mal a brasileira, organizado por Patrícia Birman, Regina Novaes y Samira Crespo, 109-135. Río de Janeiro: UERJ. 